\title{
SISTEM MONITORING MESIN MENGGUNAKAN MULTIPROSESOR SERI AVR DENGAN METODA POOLING
}

\author{
Eko Travada $\mathrm{SP}^{1}$, Darsanto ${ }^{2}$ \\ ${ }^{I}$ Teknik Informatika Universitas Pasim \\ ${ }^{2}$ Teknik Komputer Universitas Wiralodra \\ Itravada@pasim.ac.id /ekotravada@gmail.com \\ 2aziz.faiz310105@gmail.com / shanto.ft@unwir.ac.id
}

\begin{abstract}
ABSTRAK
Pemilihan teknologi untuk mendeteksi mesin industri dengan nilai ekonomis rendah, mudah perawatan tapi dengan presisi yang baik umumnya menjadi pilihan di dalam suatu industri agar biaya operasional tidak terlalu tinggi. Teknologi yang bisa digunakan adalah mikrokontroller. Mikrokontroller adalah suatu prosesor yang penggunaan bersifat khusus bukan untuk multi user seperti halnya mikroprosesor di suatu perangkat komputer. Mikrokontroler dengan kelebihannya yaitu memiliki nilai ekonomis tapi tetap memiliki presisi yang baik memiliki keterbatasan di kecepatan dan kapasitas memory. Untuk itu dibutuhkan suatu algoritma yang cukup efisien agar dapat bekerja sesuai dengan yang diinginkan. Tantangan dalam riset ini adalah menggunakan mikrokontroler secara real time (waktu nyata) untuk memonitor mesin yang berjumlah puluhan. Dalam penelitian ini dikembangkan suatu multiprosesor dalam arti menggunakan mikrokontroller lebih dari satu unit dan algoritma tertentu agar dapat secara bersamaan memonitor mesin dan saat itu juga menampilkan kondisi mesin industri yang berjumlah puluhan. Dalam penelitian ini jumlah mesin yang dimonitor yaitu 80 buah dan bisa dirubah sesuai setting di memori mikro.
\end{abstract}

Kata Kunci : Mikrokontroller, Monitor, Industri, pooling

\begin{abstract}
The selection of technology to detect industrial machinery with criteria low economic value, easy maintenance but with good precision generally becomes an option in an industry so that operational costs are not too high. The technology that can be used is a microcontroller. Microcontroller is a processor that uses is not specific to multi-user as well as microprocessors on a computer device. Microcontroller with its advantages of having economic value but still having good precision has limitations in memory speed and capacity. For that we need an algorithm that is efficient enough to work as desired. The challenge in this research is to use a microcontroller in real time (real time) to monitor machines that number in the tens. In this study a multiprocessor was developed in the sense of using more than one microcontroller and certain algoritm that it can simultaneously monitor the engine and at that time also displayed dozens of industrial engine conditions. In this study the number of machines monitored was 80 and can be changed according to the settings in micro memory. .
\end{abstract}

Keyword : Microcontroller, Monitor, Pooling, industries 


\section{PENDAHULUAN}

Dalam suatu industri berskala besar jaminan bahwa seluruh mesin produksi dapat bekerja memegang peranan penting untuk dapat menghasilkan produksi sesuai dengan target yang ditetapkan. Dalam industri berskala besar jumlah mesin berjumlah puluhan hingga ratusan bergantung Kepada kapasitas produksi di pabrik tersebut. Dengan jumlah mesin yang berjumlah besar diperlukan suatu teknik tersendiri agar proses deteksi mesin yang berjumlah puluhan dapat berjalan dengan cepat dan dapat menginformasikan dengan akurat jumlah mesin yang tidak bekerja ataupun yang sedangbekerja sehingga dapat langsung dilakukan langkah perbaikkanagar mesin produksi dapat kembali bekerja. Yang menjadi permasalahan utama dalam system monitoring mesin adalah cara mendeteksi jumlah mesin yang besar (hingga puluhan ataupun ratusan dengan algoritma efisien. Karena bila jumlah mesin besar dan algoritma tidak cukup efisien maka kecepatan deteksi akan menjadi lambat. Perangkat untuk mendeteksi mesin industri dapat menggunakan beberapa cara yaitu berupa perangkat digital berupa rangkaian logika yang didisain untuk mendeteksi mesin, komputer dan mikrokontroller. Bila alat monitor yang dibutuhkan yang diinginkan berdaya rendah, biaya murah dan akurasi baik mikrokontroller dapat menjadi suatu pilihan. Yang menjadi persoalan perangkat mikrokontroller jumlah perangkat masukkan atau dikenal dengan perangkat Iinput output (I/O) jumlahnya maksimum 32 buah sedangkan perangkat mesin industri jumlah lebih dari itu. Untuk itu perlu dikembangkan suatu teknik menggabungkan beberapa mikrokontroller sehingga menjadi suatu multiprosesor yang memiliki IO lebih dari 32 atau bahkan tidak terbatas yang dapat bekerja secara bersamaan untuk mendeteksi mesin yang bekerja. Hal yang perlu diperhatikan di mikrokontroller adalah kapasitas memori program yang relative terbatas umumnya berkisar $8 \mathrm{~Kb}$ hingga 256 $\mathrm{Kb}$. Dengan kapasitas memori terbatas maka program yang disusun untuk dimasukkan ke dalam chip mikrokontroller tidak dapat terlalu besar, sehingga juga dibutuhkan algoritma yang efisien. Untuk itu metode algoritma yang dipilih dalam riset menggunakan model polling. Model Polling adalah mendeteksi satu persatu semua mesin kemudian mengumpulkan terlebih dahulu setelah itu baru dikirimkan ke display untuk menginformasikan kondisi mesin yang bekerja.

Metodologi penyusunan jurnal ini terdiri dari bagian 1 pendahuluan kemudian penelitian yang terkait dibahas pada bagian 2, Kontribusi dari penelitian di bagian 3, methodology yang digunakan dibahas di bagian 4, disain rangkaian dibahas pada bagian 5, disain algoritma dibahas pada bagian 6 , implementasi dan pengujian dibahas pada bagian 7 dan di bagian 8 kesimpulan dan prospek penelitian berikutnya.

\section{A. Penelitian yang terkait}

Dalam memontor mesin hal yang paling utama adalah system mampu mendeteksi mesin yang aktif ataupun yang tidak aktif. Dalam mendeteksi mesin yang aktif ataupun tidak aktif ada beberapa parameter yang digunakan yaitu kecepatan mesin seperti dalam riset yang dilakukan oleh (Handian Rachmat and Asril, 2014) ${ }^{[1]}$, Kemudian dalam riset yang dilakukan oleh (Willy Docksa Marhaendra, 2016) ${ }^{[2]}$ mengusulkan memonitor mesin dengan melihat efisiensi mesin bekerja yang diukur dari data kecepatan mesin dalam suatu periode waktu tertentu. Hampir serupa dengan riset yang dilakukan oleh (Handian Rachmat and Asril, 2014) [1] tapi dalam memonitoring mesin menggunakan RFID sehingga memungkinkan monitor mesin sekaligus diketahui lokasi mesin. Riset ini dilakukan oleh (Chavhan, Chavhan and Chavan, 2013) ${ }^{[3]}$. Penggunaan Machine Learning untuk memonitor mesin diusulkan oleh (Abid et al., 2017) ${ }^{[4]}$. Metode machine learning yang digunakan yaitu menggunakan Multi Class SVM. Dalam penelitian ini dalam mendeteksi mesin dapat dilakukan bahkan saat mesin masih bekerja karena metode monitoring mengukur fault tolerance dari mesin tersebut dengan menggunakan metode class support Vecor machine.Penerapan multi prosesor untuk memonitor mesin dengan konsep multi processor dalam diambil dari penelitian yang dilakukan oleh (Patel, Parameswaran and Shee, 
2007) ${ }^{[5]}$ yang membuat suatu system keamaanan di system multiprosesor. Penerapan Multiprocessor untuk memonitor mesin di riset yang dilakukan oleh (Kovacs, 1992) ${ }^{[6]}$ mengusulkan metode monitoring multiprocessing dengan beberapa parameter yang diukur seperti suhu, kecepatan, putaran mesin. Seluruh data dari parameter tersebut digunakan untuk melihat fungswi abnormal dari mesin.

\section{B. Kontribusi Penelitian}

Kontribusi dari penelitian ini adalah

1. Menawarkan suatu teknik monitor mesin yang berjumlah besar dengan biaya rendah dengan menggunakan multiprocessor dengan menggunakan mikrokontroller AVR.

2. Metode menghubungkan antara processor bila ada penambahan jumlah mesin maka cukup dengan menduplikat perangkat keras tanpa perlu membuat rangkaian baru

3. Algoritma pendeteksian keaktifan mesin yang efisien, sehingga memperpendek ukuran program walaupun jumlah mesin yang bertambah.

\section{Permasalahan di system saat ini}

Dalam monitoring mesin yang menjadi permasalahan utama adalah

1. bagaimana mendeteksi mesin yang berjumlah besar

2. mengatur jumlah mesin yang akan dimonitor

3. Algoritma deteksi mesin yang efisien agar ukuran file tidak terlalu besar

4. Mengubungkan antar prosesor agar dapat saling memberi informasi jumlah mesin yang dimonitor.

\section{Model Yang Diusulkan}

Untuk memonitor mesin yang berjumlah besar diusulkan system terdiri dari
1. Prosesor utama yang berfungsi sebagai pengolah data monitor dan menampilkan hasil monitoring

2. Prosesor lain yang mendeteksi kondisi mesin

3. Display dalam bentuk 7 segment untuk menampilkan hasil monitoring.

4. Tiga buah tombol untuk melakukan setting mesin yang dimonitor.

Berikut gambar Model Disain yang diusulkan

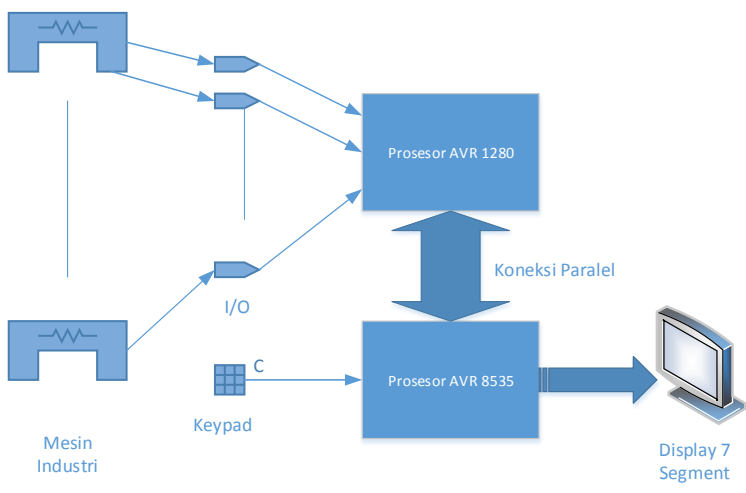

Gambar 1 Model Disain Monitoring mesin dengan multiprosesor

Seperti tampak di gambar 1 adalah model monitor mesin dengan model multiprosesor dimana prosesor seri 1280 mendeteksi mesin industri dan prosesor seri avr 8535 mengolah data dari pembacaan dari prosesor 1280 untuk kemudian secara real time dikirimkan ke display. Setiap program di prosesor 1280 daan 8535 bekerja secara mandiri dan tidak saling tergantung dalam pemrosesan datanya.

\section{METODE PENELITIAN}

Metodology dalam riset ini menggunakan langkah sebagai Berikut:

1. Mendisain perangkat keras monitor mesin yang terdiri dari modul avr seri 1280 yang memiliki 88 buah IO dan relay yang akan mengirimkan sinyal mengenai kondisi mesin

2. Mendisain pengolah data yang terdiri dari mikrokontroler seri 8535 (Winoto, 2008) ${ }^{[7]}$ yang menerima sinyal dari mikrokontroler $1280 \quad$ (Rangkuti, 2011 $)^{[8]}$ kemudian data diolah dan 
ditampilkan ke display dalam bentuk 7 segment.

3. Membuat algoritma monitor mesin dengan konsep pooling

4. Menguji coba semua perangkat dan program yang telah dimasukkan ke chip dengan cara sampling mensimulasi hidup mati mesin beberapa IO.

5. Menguji IO satu persatu untuk menjamin bahwa semua IO berfungsi.

6. Mengukur kecepatan respon display terhadap perubahan input yang diberikan ke IO.

7. Menguji akurasi proses pengolahan data input bila dilakukan perubahan jumlah mesin yang dibaca melalui keypad.

\section{HASIL DAN PEMBAHASAN}

Rangkaian yang dirakit tampak di gambar 2 yang terdiri dari modul mikro 1280, dan gambar 2 keseluruhan rangkaian.

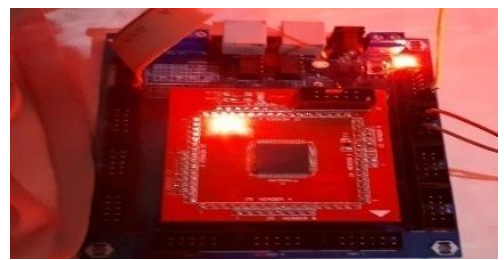

Gambar 2 Modul Mikrokontroller seri 1280

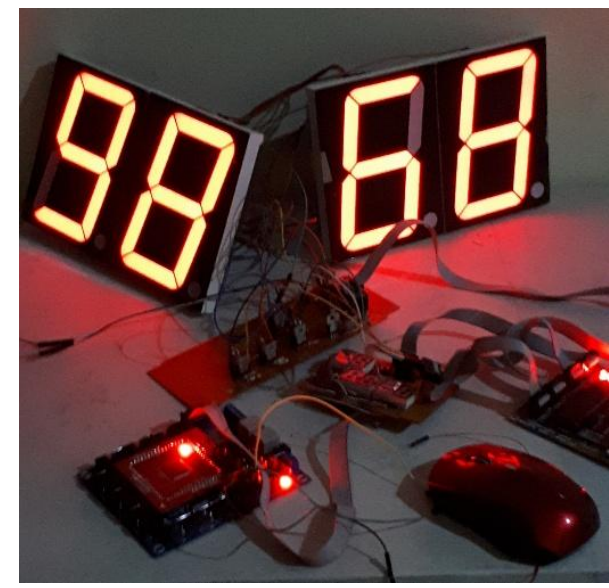

Gambar 3 Keseluruhan rangkaian monitor mesin

Algoritma untuk pooling mesin dengan cara mendeteksi satu persatu IO yang terhubung ke mesin bila mesin hidup maka nilai mesin yang akan diincrement sebaliknya kalau mesin mati maka proses increment dilewat. Hasil dari proses increment dikirimkan ke proses berikutnya untuk diolah sesuai setting mesin. Algoritma untuk monitor mesin disusun seperti tampak di gambar 4 .

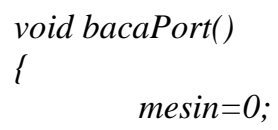

Gambar 4 Pooling mendeteksi mesin yang hidup

Kalau diperhatikan untuk mendeteksi 80 input cukup dengan membaca port yang tersedia yaitu 10 port, kemudian untuk pembacaan tiap pinnya IO dengan perintah

$$
\begin{gathered}
\text { for (int enggineScan }=0 ; \text { enggineScan }<8 ; \\
\text { enggineScan }++)
\end{gathered}
$$


yang akan menaikkan nomor pin di setiap port dalam instruksi Berikut

$$
\text { if (bit_is_clear(PGM1,enggineScan)) }
$$

Informasi jumlah mesin yang dibaca tersimpan di variabel

$$
\text { mesin }++ \text {; }
$$

Sedangkan rumus untuk menampilkan jumlah mesin yang tidak bekerja diformulasi sebagai Berikut :

$$
\begin{aligned}
\text { machShutDown } & =\text { defaultEnggineMachine } \\
& - \text { readEnggine }
\end{aligned}
$$

machShutDown adalah jumlah mesin yang tidak bekerja, defaultEnggineMachine adalah jumlah setting mesin yang dibaca/dideteksi dan readEnggine adalah jumlah mesin yang terbaca dari variabel mesin. Selain menampilkan jumlah mesin yang mati display juga menampilkan mesin yang bekerja diformulasi sebagai Berikut:

$$
\begin{aligned}
\text { enggineOn }= & \text { defaultEnggMachine } \\
& - \text { machineShutDown } ; \\
\text { enggineOn } 2= & (\text { enggineOn } \\
& / \text { defaultEnggineMachine }) \\
& * 100
\end{aligned}
$$

enggineOn adalah informasi mesin yang hidup dan enggineOn2 adalah persentasi mesin yang aktif.

Pengujian mesin tampak di tabel 1 berikut

Tabel 1 Pengujian Sistem

\begin{tabular}{|l|l|l|l|l|l|}
\hline No & $\begin{array}{l}\text { Set } \\
\text { Mesin } \\
\text { Aktif }\end{array}$ & $\begin{array}{l}\text { Mesin } \\
\text { tidak } \\
\text { bekerja }\end{array}$ & $\begin{array}{l}\text { Display } \\
\text { Mesin } \\
\text { Aktif }\end{array}$ & $\begin{array}{l}\text { Display } \\
\text { Persen }\end{array}$ & $\begin{array}{l}\text { Waktu } \\
\text { Respon } \\
\text { (IO) }\end{array}$ \\
\hline 1 & 80 & 1 & 79 & 99 & $\begin{array}{l}<1 \\
\text { detik }\end{array}$ \\
\hline 2 & 80 & 4 & 76 & 95 & $\begin{array}{l}<1 \\
\text { detik }\end{array}$ \\
\hline 3 & 64 & 2 & 62 & 97 & $\begin{array}{l}<1 \\
\text { detik }\end{array}$ \\
\hline 4 & 64 & 4 & 60 & 94 & $\begin{array}{l}<1 \\
\text { detik }\end{array}$ \\
\hline
\end{tabular}

Berdasarkan tabel terlihat bahwa display sudah menunjukkan waktu dengan akurat dan waktu respon mikrokontroller terhadap perubahan input dibawa 1 detik. Berdasarkan beberapa sumber bahwa dalam skala industri dikatakan real time kalau waktu respon antara kondisi sebenarnya dan waktu display adalah sesuai waktu yang diinginkan atau diistilahkan dengan deadline (Petters., 2003) ${ }^{[9]}$. Untuk memonitor mesin industri waktu deadline informasi adalah selama perubahan itu belum menimbulkan dampak Kepada target, biaya maka dapat dikatakan real time. Maka waktu antara perubahan dan informasi masih dibawah 1 detik masih dapat dikatakan real time system.

Pengukuran daya system monitoring ini secara perhitungan sebagai Berikut:

1. Tegangan untuk 2 perangkat mikro yaitu 12 volt dengan menggunakan power supply sebesar 1 ampere.

2. Daya untuk display sebesar 12 volt dengan power supply daya 2 ampere

Maka kebutuhan daya yang dibutuhkan untuk menjalankan system monitoring yaitu sebesar 36 watt yang didapat dari

$$
121+12 * 2=36 \text { Watt. }
$$

\section{KESIMPULAN}

Dari Penelitian ini dapat tampak bahwa dengan implementasi multiprosesor dengan menggunakan mikrokontroller dan algoritma ppoling dapat digunakan untuk memonitor mesin dan memenuhi kriteria real time system yaitu waktu respon dibawah 1 detik. Sedangkan untuk daya yang digunakan untuk memonitor mesin sebesar 36 Watt dan daya yang dibutuhkan relative kecil dibandingkan jumlah mesin industri yang dideteksi yang berjumlah 80 buah.

Riset berikutnya yang dapat dikembangkan adalah mengembangkan system monitoring mesin dengan kemampuan merekam kondisi mesin di waktu tertentu, sehingga dapat bila terjadi perubahan hasil produksi dapat dihubungkan dengan jumlah sebenarnya mesin yang aktif di waktu tersebut. 


\section{DAFTAR PUSTAKA}

[1] Handian Rachmat, H. and Asril, H. (2014) 'Implementasi Counter Production Monitoring pada Mesin Tekstil berbasis Mikrokontroler', 2(2).

[2] Willy Docksa Marhaendra, Y. R. B. (2016) 'Aplikasi Monitoring Mesin Produksi berbasis Web ( Studi Kasus : PT Pura Barutama Divisi Indostamping )', (672012106).

[3] Chavhan, R. D., Chavhan, S. U. and Chavan, G. B. (2013) 'Real Time Industrial Monitoring System', International Journal of Computer Trends and Technology, 4(7), pp. 2073-2077. Available at: http://www.ijcttjournal.org.

[4] Abid, A. et al. (2017) 'Real time health monitoring of industrial machine using multiclass support vector machine', 2017 2nd International Conference on Control and Robotics Engineering, ICCRE 2017, (April), pp. 77-81. doi: 10.1109/ICCRE.2017.7935046.

[5] Patel, K., Parameswaran, S. and Shee, S. L. (2007) 'Ensuring secure program execution in multiprocessor embedded systems', Proceedings of the 5th IEEE/ACM international conference on Hardware/software codesign and system synthesis - CODES+ISSS '07, p. 57. doi: 10.1145/1289816.1289833.

[6] Kovacs, C. G. M. ; G. H. R. ; G. H. ; G. (1992) 'Multiprocessor based machine tool monitoring system'. Available at: https://ieeexplore.ieee.org/abstract/docum ent/1 71879.

[7] Winoto, A. (2008) Mikronkontroller AVR ATMEGA dan Pemrogramannya dengan Bahasa C pada WIN AVR.

[8] Rangkuti, S. (2011) Mikrokontroller ATMEL AVR.

[9] Petters., S. M. (2003) 'Real-Time Systems', Computer, pp. 1-66. 